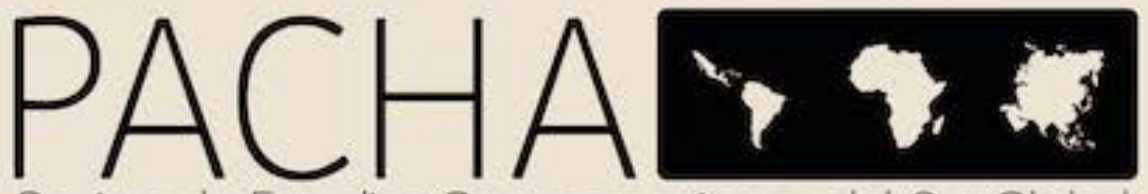

Revista de Estudios Contemporáneos del Sur Global Joumal of Contemporary Studies of the Global South Revista de Estudos Contemporâneos do Sul Global 


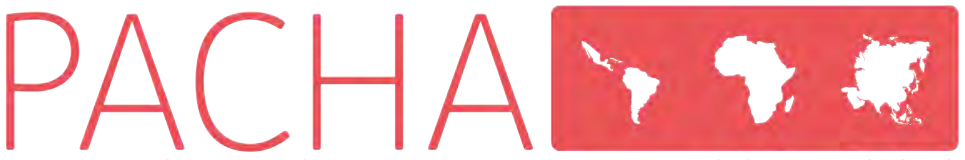

Revista de Estudios Contemporáneos del Sur Global

Joumal of Contemporary Studies of the Global South

\section{Equipo Editorial}

Carolina Díaz R.

Directora Editorial

CICSH-AL Centro de Investigaciones en Ciencias Sociales y Humanidades desde América Latina, Ecuador revistapacha@religacion.com; carolinadiaz@religacion.com

Roberto Simbaña Q.

Coordinador Editorial

CICSH-AL Centro de Investigaciones en Ciencias Sociales y Humanidades desde América Latina, Ecuador robertosimbana@religacion.com

\section{Editores Asociados}

Paola Andrea Tovar. Universidad De Montreal, Colombia. Editora Asociada en Antropología

Mitchell Alberto Alarcón Díaz. Universidad Nacional Mayor de San Marcos, Perú. Editor Asociado en Educación

Marcela Cristina Quinteros. Universidade Estadual de Maringá, Brasil. Editora Asociada en Historia Latinoamericana

Aboutaleb Sedatee Shamir. Islamic Azad University, Iran. Editor Asociado en Educación y Medio Oriente

Mateus Gamba Torres. Universidade de Brasilia - UNB, Brasil. Editor Asociado en Historia Mirna Yazmin Estrella Vega. Universidad Nacional Autónoma de México, México. Editora Asociada en Sociología

Rodrigo Navarrete Saavedra. Universidad Aus tral de Chile, Chile. Editor Asociado en Ciencias Políticas

Aygul Zufarovna Ibatova. Tyumen Industria University, Rusia. Editora Asociada en Humahidades sobre Asia
Shokhrud Fayziev Farmanovich. Tadqiqot, Tashkent, Uzbekistan. Editor Asociado en Desarrollo sobre la Comunidad de Estados Independientes, Asia.

Mª Aránzazu Serantes López. Woolf University, España. Editora Asociada en Humanidades digitales

Fabricio Espinosa Ortiz. Consejo Nacional de Ciencia y Tecnología, México. Editor Asociado en Geografía Humana

Marcelo Starcenbaum. Universidad Nacional de La Plata, Argentina. Editor Asociado en Filosofía e Historiografía

Siti Mistima Maat. Universiti Kebangsaan Malaysia, Malaysia. Editora Asociada en Innovación de aprendizaje

Carla Vanessa Zapata Toapanta. Universidad de Salamanca, España. Editora Asociada en Latinoamericanismo

\section{Consejo Editorial}

Andrea Paola Cantarelli, Universidad Nacional de Cuyo, Argentina
Federico Cabrera, Universidad Nacional de San Juan/CONICET, Argentina

Gamaniel David Suárez Cobix, Universidad Veracruzana, México

Gloria Concepción Tenorio Sepúlveda, Tecnológico de Estudios Superiores de Chalco, México

Héctor García Cornejo, Universidad Michoacana de San Nicolás de Hidalgo, México

Jorge Gilberto Bonilla Macas, Universidad Católica de Cuenca, Ecuador

José Alexander Rubiano Pedroza, Universidad de Pamplona, Colombia

María Dolores Sancho, Universidad Nacional del Comahue, Argentina

Mauricio Sandoval Cordero, Facultad Latinoamericana de Ciencias Sociales, Costa Rica

Rivera Varela Bertha Leticia, Universidad Abierta a Distancia, México

Tomás Sebastián Torres López, Universidad Alberto Hurtado, Chile

\section{CONSEJO ASESOR INTERNACIONAL}

\author{
Alejandro Mejía Tarazona \\ Facultad Latinoamericana de Ciencias Sociales, Ecuador \\ Alexander Luna Nieto \\ Fundación Universitaria de Popayán, Colombia \\ Celeste De Marco \\ CONICET/Universidad Nacional de Quilmes-CEAR, Argentina \\ Christian Andres Quinteros Flores \\ Universidad de Chile, Chile \\ Daniel Orizaga Doguim \\ Centro de Investigaciones Multidisciplinarias-UAQ, México \\ Francisco Javier Jover Mart \\ Universidad de Castilla-La Mancha, España
}

Gaya Makaran

Centro de Investigaciones sobre América Latina y el Caribe CIALC, UNAM, México

Jaime Araujo Frias

Universidad Nacional de San Agustín, Perú

João Luis Binde

Universidade Federal De Pernambuco, Brasil

Luisina Castelli Rodríguez

Universidad de la República, Uruguay

Mariana Jesica Lerchund

Universidad Nacional de Río Cuarto, Argentina

Marina Acosta

Universidad de Buenos Aires, Argentina

Noelia Marina Cortinas

Universidad de Buenos Aires, Argentin

Paulo Alves Pereira Júnior

Universidad Estatal Paulista, Brasil

Sergio Monroy Isaza

Universidad de Ibagué, Colombia

Suyai Malen Garcia Gualda

IPEHCS-CONICET-UNCO, Argentin 


\title{
Muertes silenciadas. Notas para pensar los feminicidios indígenas en Argentina
}

\author{
Silenced deaths. Notes to think about indigenous femicides in Argentina
}

Suyai García Gualda

Instituto Patagónico de Estudios de Humanidades y Ciencias Sociales, CONICET UNCo - Argentina

suyai.garcia@fade.uncoma.edu.ar

\section{RESUMEN}

\#Niunamenos es un grito que ruge fuerte, que une, contiene y moviliza a muchas mujeres a lo largo y ancho del continente latinoamericano. Pese a ello, nos apremia indagar en las diversas intensidades de este grito, nos urge atender y amplificar los susurros que resuenan tenuemente tierra adentro. Entendemos que ya es hora de hablar y visibilizar los feminicidios indígenas en un país racista y patriarcal como la Argentina. Por esta razón, en el presente trabajo nos proponemos ahondar en la realidad de las mujeres originarias, especialmente en sus denuncias frente a las múltiples formas de violencia que padecen producto del avance del modelo extractivista con el beneplácito de los gobiernos de turno. En este documento desarrollamos reflexiones teóricas en las que buscamos articular la teoría política con aportes centrales de los estudios feministas y de género.

Palabras clave: feminicidios, mujeres indígenas, violencia, género, extractivismo

\section{ABSTRACT}

\#Niunamenos it is a shout that roars laud, that unites, contains, and mobilizes many women throughout the Latin American continent. Despite this, we are compelled to investigate the various intensities of this cry, we are urged to attend and amplify the whispers that faintly echo inland. We understand that it is time to speak up and make indigenous femicides visible in a racist and patriarchal country like Argentina. In this document, we intend to delve into the reality of indigenous women, especially in their complaints against the multiple forms of violence they suffer as a result of the extractivist model which advance with the approval of the current governments. In this article we develop theoretical reflections in which we seek to articulate political theory with feminist's and gender studies' central contributions.

Keywords: femicides, native women, violence, gender, extractivism 


\section{INTRODUCCIÓN}

Ni una menos es una multitud de cuerpos. Cuerpos impugnando las violencias reunidos en el espacio público. Cuerpos que sobreviven en el vilo de la dominación patriarcal. Cuerpos reclamando la cuenta

(Bidaseca, [2015] 2017: 36)

No hay mejor manera de comenzar a pensar y a problematizar(nos) que por medio de la duda. Las preguntas son las que nos animan y motorizan a investigar, a exigir respuestas. Entonces, es válido comenzar este trabajo preguntándonos ¿por qué nos matan? Aunque, ciertamente, en estas pocas páginas no vamos a poder dar una respuesta certera y completa a tremendo interrogante. No obstante, esta duda que nos quita el sueño a tantos/as, es el puntapié inicial que necesitamos para introducirnos en la complejidad de nuestras muertes, en las redes que tejen las alianzas y complicidades que la(s) masculinidad(es) hegemónica despliega a lo largo y ancho de todo el globo para silenciar nuestros gritos. Los gritos nos inquietan, sobre todo aquellos que resuenan fuerte pero que no se escuchan. Hablar de la muerte como expresión última de la violencia machista se ha vuelto una tarea indispensable en estos últimos años. Sin embargo, en la coyuntura actual, denunciar los femicidios no debe, como sostiene Verónica Gago (2019), reducirnos y confinarnos a la cuantificación necropolítica. Entonces, siguiendo la lógica de la autora, surge la imperiosa necesidad de dar cuenta de la pluralización de las violencias, es decir, de cartografiar las múltiples formas de desigualdad y opresión que atraviesan a los cuerpos-territorios femeninos y feminizados.

En este punto buscamos detenernos a lo largo de las siguientes páginas. No tenemos dudas de que \#Niunamenos es un grito que ruge fuerte, que nos une, contiene y moviliza a muchas. Pese a ello, nos apremia indagar en las diversas intensidades de este grito, nos urge atender y amplificar los susurros que resuenan tenuemente tierra adentro. Es hora de hablar y visibilizar los feminicidios indígenas en un país racista y patriarcal como la Argentina. Por esta razón, en el presente trabajo nos proponemos ahondar en la realidad de las mujeres originarias, especialmente en sus denuncias frente a las múltiples formas de violencia que padecen producto del avance del modelo extractivista con el beneplácito de los gobiernos de turno.

La ausencia de las voces indígenas en la denuncia colectiva "Ni una menos, Vivas nos queremos"; nos obliga como cientistas sociales feministas a cuestionar cuáles son nuestras lentes para mirar la realidad en y desde nuestros territorios. Estamos convencidos/as de que tener en cuenta las continuidades históricas nos permitirá visibilizar la violencia sistemática, el terror étnico (Segato, 1998) y de género sobre el cual se forjó el Estado Argentino, el cual, como ya dijimos, continúa erguido sobre estructuras de poder basadas en el racismo y la violencia machista. En suma, escribimos estas páginas con el ánimo de aportar al debate sobre la premura de incorporar de manera transversal la perspectiva interseccional de género en los diferentes organismos del estado e incluso en las diversas expresiones del feminismo. De lo contrario, a nuestro parecer, continuaremos legitimando decisiones políticas que excluyen y agravan la situación de un amplio sector en situación de vulnerabilidad y desventaja: las mujeres indígenas.

\section{Perspectiva teórica-metodológica}

El presente escrito es un trabajo teórico de carácter flexible, ya que, a lo largo de su desarrollo articula notas propias de la teoría fundamentada con datos construidos a partir de la realización de trabajo etnográfico en comunidades originarias en la provincia de Neuquén. Vale decir que nos interesa desplegar una estrategia metodológica -cualitativa- que nos permita aproximar los aportes del campo de la ciencia y teoría política con la producción proveniente de los estudios de género y feministas. En este sentido, reconocemos que la inclusión de esta temática en las arenas de la ciencia política no ha sido una terea sencilla, sin embargo en los últimos diez años hemos estado especialmente dedicados/as a tal misión.

En esta oportunidad, a los fines del presente artículo, haremos referencia a diferentes fuentes secundarias como documentos elaborados por organismos vinculados a los pueblos indígenas, en especial a las mujeres. Asimismo, hemos considerado (como complemento) para nuestras reflexiones el uso de materiales audiovisuales y notas de diarios y periódicos. Cabe señalar que se trata de un tema de trabajo que viene a cuenta de nuestra investigación sobre la participación política de las mujeres indígenas en los conflictos territoriales en la norpatagonia argentina. Por tanto, este escrito se enmarca en una investigación de mayor envergadura que ha iniciado hace una década y que continúa explorando nuevas aristas, con el fin de contribuir a la visibilización de las múltiples formas de opresión que padecen las mujeres indígenas en la actualidad y sus correspondientes estrategias de resistencia. 
Nuestro enfoque teórico-metodológico se nutre, fundamentalmente, de la perspectiva interseccional del género, puesto que advertimos la necesidad de comprender la convergencia de las diferentes formas de opresión/desigualdades padecidas por las mujeres, ligadas al sexismo, clasismo y racismo (Zambrini, 2015). A nuestro juicio, la interseccionalidad nos muestra la importancia de desarrollar un análisis que incluya las diversas (y multidimensionales) estructuras de poder, es decir, nos motiva a dar cuenta de la realidad imbricada por relaciones de poder en un contexto histórico específico. En el caso que nos atañe, nos centraremos en la actual etapa de acumulación capitalista marcada por la desposesión y el despojo (Harvey, 2004; Roux, 2008), sin perder de vista las continuidades históricas que evocan a una larga memoria extractivista (Seoane, 2012).

\section{El valor del cuerpo de las mujeres}

En la embrionaria Argentina, como en el resto de América Latina, el estado moderno se construyó a partir de un sistemático y violento proceso de racialización de la vida sociopolítica (Quijano, 1999). Dicha racialización logró jerarquizar a las sociedades en base a una clasificación asentada en la distinción entre el "uno" blanco, burgués, varón, europeo, civilizado y asalariado y el "otro" no-blanco, feminizado, salvaje y excluido de las relaciones asalariadas. De este modo, los Estados (uni-nacionales y uni-culturales) se impusieron por la fuerza y fueron legitimados por el constitucionalismo moderno. Desde entonces, en toda América Latina, la raza como patrón de poder ubica a los/as no-blancos en calidad de ciudadanos/as de segunda y, especialmente en Argentina, configura a la identidad nacional basada en un discurso "blancocivilizado" que todavía detenta una potente presencia en el seno de diversas estructuras de poder.

La teoría de la colonialidad del género sostiene que el patrón global del capitalismo inaugurado por la Conquista de América utilizó la diferencia de género entre las razas para marcar la exclusión del "otro" racial del dominio de la especie humana (Di Pietro, comunicación personal, enero 2012). Las clases dominantes han asumido el poder de identificar, cuantificar, jerarquizar, nominar, asignar fronteras y posiciones sociales con arreglo a identidades étnico-raciales (Guerrero citado en Pequeño Bueno, 2007, p. 29). Dicho de otro modo, como sostiene Berlanga Gayón (2015), la valoración social de los/as sujetos/ as -desde épocas de la conquista hasta nuestros días- es determinada por una clasificación social que ha sido históricamente establecida a partir del género, la raza, la clase, etc. Todavía vemos cómo las personas que tienen rasgos asociados a lo nativo u originario, es decir, aquellos cuerpos cuya estética corresponde al fenotipo americano son despreciados, infra-valorados y susceptibles de ser explotados.

El avance territorial que supuso la conquista en tanto expansión de la frontera económica y política llevó a la puesta en marcha de ciertos mecanismos de terror (étnico y de género). Por esta razón, no es casual que en plena conquista, los cuerpos de las mujeres hayan sido objetos preciados y útiles para el despliegue de técnicas de poder y de las relaciones de poder capitalistas (Federici, 2010). Los cuerpos femeninos (y feminizados) han sido históricamente constituidos como lugares aptos para la escritura que permite delinear los territorios. En el caso de Argentina, la expansión del Estado en el siglo XIX implicó, entre otras cosas, la invención de Patagonia, pues el ensanchamiento de la(s) “frontera(s)" refería, en este caso, a una ampliación territorial e ideológica. Esto significa que Patagonia además de ser pretendida en términos económicos, se proyectaba como límite entre la civilización y la barbarie (Lenton, 2010, p. 31).

La mal llamada Conquista del Desierto encabezada por Julio A. Roca, promovió una doble feminización de los territorios -y las territorialidades-. Por un lado, los territorios del sur, los territorios indígenas, fueron vistos y pensados como fecundables y susceptibles de ser penetrados, conquistados, expropiados y sometidos. Y, por otro, la idea dominante que valió como justificación de la conquista -y posterior colonización- apeló a la Nación, vista como una mujer "herida en su territorialidad por bárbaros que le impiden gozar de lo que le pertenece" (Lenton, 2010, p. 34). De esta forma observamos, claramente, la doble feminización territorial: la del desierto, exhibido como una hembra a conquistar y someter, y la de la nación (unicultural), figurada a través de una visión idílica de una mujer blanca y civilizada privada de sus derechos por bárbaros, es decir, una cautiva. Dicha feminización territorial ha sido una innegable expresión de arreglos étnicos raciales, ya que ha puesto de manifiesto la relación entre cuerpo-género e identidad étnico-racial. De hecho toda América ha sido figurada históricamente en un cuerpo de mujer.

La sexualidad vertida a través de la inseminación del cuerpo-territorio femenino fue una expresa manifestación de apropiación y dominio territorial. De esta forma el control de los conquistadores fue inscripto en los cuerpos de las mujeres indígenas (Segato, 2004). Las mujeres a través de sus cuerpos fueron campos en los que se disputaron honores, dignidades y resistencias; fueron ( $y$ son) los escenarios de las contiendas políticas por excelencia. Ergo, la conquista se realizó en gran parte a partir del cuerpo de las mujeres (Berlanga Bayón, 2015, p. 15). Los actos de violencia sexual e, incluso, el mestizaje sirvieron como instrumentos de destrucción cultural progresiva, cuyo apoyo estaba dado y legitimado en el nuevo orden 
social a instalar. El mestizaje fue una forma de disciplinamiento, de control, de abuso y de colonización llevado a cabo en los cuerpos de las mujeres indígenas. Al respecto, Alba Carosio (2011) explica que los vientres de las mujeres fueron instrumentos que permitieron asentar el poder y el dominio de los conquistadores.

La modernidad capitalista y patriarcal no sólo considera a la naturaleza como objeto de dominio sino también a los cuerpos, de modo que éstos son considerados campos de dominio que permiten la obtención de ganancia. En relación a esta apropiación de los cuerpos-territorios indígenas en épocas de la conquista y colonización, Carosio aproxima la noción de plusvalía sexual étnica. La violencia que supuso la penetración colonial tuvo un "fuerte contenido de violencia sexual, violencia erótica, fortalecimiento de la violencia genérica del deseo y de legitimarla con la imposición de la heterosexualidad obligatoria y la monogamia para las mujeres" (Paredes, 2012, p. 96). En otras palabras, la violencia sexual que generó la penetración colonial de los cuerpos-territorios se disfrazó de erotización a fin de justificar y negar un genocidio. La feminización de los/as otros/as y de sus cuerpos-territorios garantizó la subordinación de las mujeres hasta la actualidad: “[I]a violencia e invasión a nuestro cuerpo-territorio, significó el despojo de todo nuestro ser mapuche, la autoestima y el amor a nosotras mismas, nos fue arrancada con el aval de la sociedad que hasta hoy calla y justifica" (Millán, 2010, p.133).

La penetración de los cuerpos-territorios de las mujeres indígenas fue parte de los procesos de ocupación, exterminio y/o sujeción de un pueblo sobre otro (Segato, 2016). Al respecto, Francesca Gargallo (2015) añade que los cuerpos de las mujeres fueron cuerpos-territorios doblemente feminizados: por ser cuerpos portadores de genitales femeninos y por ser "cuerpos indios". No podemos negar que si bien los cuerpos responden a la materialidad del ser humano, están modelados por lo cultural, los significados que se les atribuyen y la socialización del mismo. Por tanto, es factible señalar que en todo conflicto bélico "lo femenino" es destruido física y psíquicamente a fin de dañar la identidad de la etnia o nación atacada (Seifert, 1996). Al respecto, la antropóloga Rita Segato en el juicio de Sepur Zarco, en Guatemala, realizó un exhaustivo peritaje antropológico-cultural de género en el cual aseveró: "el cuerpo de las mujeres alegoriza el cuerpo social y la dominación sobre el mismo simboliza el poder jurisdiccional de un territorio" (2016, p. 2). El punto clave consiste en que, en todo acontecimiento bélico, como código implícito a lo largo de los años, las mujeres y los niños/as han sido considerados/as parte del botín, un anexo del territorio conquistado.

El genocidio indígena supuso, además de la tortura y otras formas de horror y muerte, la reducción a la servidumbre de las mujeres indígenas, su sometimiento como mano de obra semi-esclava en campos de concentración y su posterior reparto entre la elite porteña. La práctica de "reparto de chinas y sus chinitos/as" hace visible cómo el Estado y los sectores aliados (privados), convirtieron a los/as indígenas en cuerpos disponibles (los proletarizaron) y se apropiaron de ellos. Ni modo, desde su fundación el Estado se apropia de los cuerpos-territorios de las mujeres para lucro y beneficio del capital: "el cuerpo es para las mujeres lo que la fábrica es para los trabajadores asalariados varones: el principal terreno de su explotación y resistencia" (Federici, 2010, p. 29). Los cuerpos femeninos son, además, aquellos que por su capacidad reproductiva pueden perpetuar un pueblo, una nación, por lo que no es casualidad que la violencia genocida recaiga sobre ellos (Berlanga Bayón, 2015, p. 17).

Lo cierto es que a pesar del tiempo, la compleja y enmarañada realidad latinoamericana no hace más que demostrar que la pretendida homogeneidad y unidad cultural, sobre la cual fueron construidos los Estados Nacionales, ha fracasado. En los últimos tiempos, las disputas por el reconocimiento de las diferencias y la existencia de sujetos/s plurales han adquirido beligerancia política y visibilidad epistemológica. Beligerancia política, por confrontar las múltiples estructuras de dominación y visibilidad epistemológica, porque revelan dimensiones de la realidad que durante siglos han sido invisibilizadas por la cultura dominante (Vargas Valente, 2011, p. 4). En este contexto, Argentina ha sido terreno fértil para la emergencia de luchas indígenas, las cuales en sus demandas articulan dos dimensiones fundamentales de la justicia social: el reconocimiento y la redistribución. Pues, estos grupos o colectivos se ven afectados en las dos dimensiones: sufren la falta de reconocimiento identitario y cultural $y$, al mismo tiempo, padecen de una mala distribución económica (saqueo territorial, pobreza, exclusión y marginalidad, etc.); el no reconocimiento genera una vulneración distributiva y viceversa.

En suma, en una coyuntura marcada por al avance neo-extractivista, los cuerpos-territorios de las mujeres indígenas sufren una nueva arremetida. $Y$, en esta fase del neoliberalismo tardío, queda en evidencia que el cuerpo (y su apariencia) son determinantes en territorios que han tenido y tienen un lugar marginal en el sistema capitalista. Así, en un sistema basado en la explotación, los pueblos originarios son explotables por definición, por tanto sus cuerpos-territorios son desechables, es decir, anexos a las zonas de sacrificio. Sin perder de vista las continuidades históricas, nos preguntamos, una y mil veces, 
por los cuerpos en los que se despliega la violencia, aquellos víctimas de torturas y utilizados para el disciplinamiento social. No preguntamos, entonces, por los cadáveres que no cuentan, los innombrables, aquellos incómodos cadáveres.

\section{Los feminicidios indígenas}

Los cuerpos de las mujeres están repletos de significados culturales y sociales. Los cuerpos de las mujeres son sitios donde se dan batallas políticas y morales. Son estos cuerpos, que la comunidad, el estado, la familia, la iglesia y el mercado mediante controles patriarcales, los transforman en expresiones de las relaciones de poder. Es así que los cuerpos de las mujeres están en el centro de propuestas autoritarias o democráticas.

(Segato, s.f)

Es imposible comenzar a problematizar una temática tan sensible como los feminicidios indígenas sin previamente realizar un sucinto recorrido por el concepto que se nos presentan como clave. Cabe mencionar que sobre este tema existe un cuantioso corpus teórico, dedicado principalmente a la tipificación del delito (femicidio y feminicidio) en América Latina. En todos los casos se hace referencia como antecedente directo a la categoría de femicide, originada en el seno de los estudios de género, acuñada por Diana Russell y Jane Caputi, durante los años noventa. El origen del término está estrechamente vinculado con la urgencia de probar que la gran mayoría de los asesinatos de mujeres poseen como común denominador a la misoginia y son, en efecto, la máxima expresión de la violencia sexista (Toledo Vásquez, 2009, p. 24). La "traducción" al español de este concepto ha generado numerosos debates teóricos que, vale subrayar, todavía no han llegado a su fin.

En México, especialmente en Ciudad Juárez, la exhibición de cádaveres de mujeres con huellas de extrema violencia captó la atención de numerosas referentes feministas, entre ellas Marcela Lagarde. Esta antropóloga adaptó el término femicide y comenzó a hacer circular el concepto de feminicidio y violencia feminicida para explicar los crímenes aberrantes que comenzaban a repetirse en el espacio público mexicano. Esta autora sostiene que los feminicidios son la culminación de múltiples y sistemáticas formas de violencia que atentan contra los derechos humanos de mujeres y niñas. En palabras de Lagarde: "la violencia está presente antes del homicidio de formas diversas a lo largo de la vida de las mujeres. Después de perpetrado el homicidio, continúa como violencia institucional a través de la impunidad que caracteriza casos particulares" (s/f: 1). La crueldad a la que son sometidos los cuerpos-territorios femeninos (y feminizados) pone de manifiesto, como dice Segato, "un pacto de semen", un "pacto de sangre sobre la sangre de la víctima", es decir, un sello de lealtad al grupo que se traduce en impunidad. Y esto, lamentablemente, se ha normalizado en nuestros países.

La violación reproduce relaciones de subordinación: "sujetos cuyos cuerpos son abusados y sujetos que abusan, sin consentimiento, de esos cuerpos". Se trata del uso y abuso de unos cuerpos (sujetos masculinos) sobre otros (sujetos feminizados, con signos de femeneidad) (Segato, 2003), donde quedan al descubierto las relaciones de poder. Sin duda, podemos trazar una analogía con lo que ocurre con los territorios indígenas en Argentina -y en toda América Latina-. La violación puede ser interpretada, siguiendo a Rita Segato como una agresión contra otro(s) hombre(s) "cuyo poder es desafiado y su patrimonio usurpado mediante la apropiación de un cuerpo femenino" (2003, p. 32). En este sentido, la violación de los cuerpos femeninos y feminizados es, al mismo tiempo, la violación del territorio; y la violación del territorio supone, también, la violación de los cuerpos. Por esto, pensamos que las mujeres indígenas encarnan en sus cuerpos-territorios múltiples expresiones de violencia; violencia interseccional que articula las relaciones de género, clase y raza.

Este pacto intra genérico busca reafirmar la masculinidad hegemónica, una masculinidad o estatus social que se encuentra puesto en cuestión por mujeres que se animan a cuestionar el orden establecido. Las mujeres defensoras de derechos, las lideresas indígenas que luchan por la preservación de los bienes comunes de la naturaleza, aquellas que no dudan en manifestarse públicamente contra los intereses estatales y corporativos, esas mujeres son una amenaza. Se trata de mujeres que amenazan un orden social, político y económico que se sostiene sobre la división sexual del trabajo y el androcentrismo; mujeres que se atreven a levantar la voz. Estas mujeres deben ser disciplinadas. Por ello, explica Gayón (2015), la teatralidad de sus muertes, la exposición, la saña en sus cuerpos-territorios. La inacción, complicidad e impunidad que subyacen en los feminicidios colocan frente a nosotros/as a un actor fundamental, el Estado. Un Estado opresor, violador y femicida como denuncia el colectivo Las Tesis.

El feminicidio es una forma de dominio territorial desde una lógica patriarcal y en esta ecuación, la 
acción u omisión del Estado es nodal. Si consideramos, como explican Segato y Gayón, que el o los receptores "del mensaje" inscripto en los cuerpos de las mujeres asesinadas son quiénes dotan de sentido al acto, entenderemos quiénes son los que quieren perpetuar su poder sobre otros. No es casual que las víctimas sean mujeres pertenecientes a sectores desaventajados de la sociedad. Por esta razón, sostenemos que los feminicidios son sistemáticos y sistémicos, están garantizados ( $y$, en muchas ocasiones, promovidos) por la lógica machista y patriarcal de la estatalidad. Así se puede observar a la muerte como el escalón último, la consecuencia, de múltiples vulnerabilidades y formas de opresión a las que mujeres y niñas de ciertos sectores sociales son expuestas a lo largo de sus vidas tanto por el Estado (en sus distintos niveles de actuación) como por ciertos sectores económicos. Al respecto Lagarde ha denunciado:

\footnotetext{
Estas formas de violencia se dan en el marco de un alto rango de exclusión, marginación, explotación y extrema pobreza de las mujeres, base de índices elevados de morbilidad y mortalidad femenina como la materna e infantil debidas al crecimiento precario, la desnutrición, los padecimientos y las enfermedades no atendidas (2005, p. 2).
}

En este sentido, insistimos en la relevancia abordar la realidad de las mujeres indígenas desde una perspectiva interseccional del género porque entendemos que atender únicamente a su condición de mujeres no basta para explicar la violencia que padecen sus cuerpos-territorios. Consideramos que es necesario tener en cuenta la relación e intersección entre el género(s) y otras formas de violencia y discriminación estructurales, por caso el racismo y la explotación económica. Las víctimas de feminicidio son, en su mayoría, mujeres precarizadas, marginalizadas, pobres, negras, indígenas, trans-travestis, etc. Posicionarnos desde una perspectiva interseccional nos pone de cara a la(s) identidad(es), pues supone dirigirnos hacia las vivencias, experiencias y pertenencias de los/as sujetos/as. Y, siguiendo a Floya Anthias (2006), nos interesa considerar la multiplicidad de posiciones y pertenencias de estas mujeres, identificar la resonancia política de las de las identidades. Pues, no es casual, que en un país que se jacta de su blanquitud, sean "las otras" un blanco fácil de la violencia feminicida.

En una coyuntura marcada por el avance del modelo neo-extractivista, son los cuerpos-territorios de las mujeres indígenas espacios en los que se despliegan relaciones de poder, al igual que durante el proceso de conquista y colonización en el siglo XIX. Los cuerpos femeninos racializados y pauperizados son considerados cuerpos sacrificables. Por esta razón, las indígenas organizadas en Argentina denuncian a viva voz, y en el marco de las masivas marchas bajo la premisa \#NiUnaMenos, la urgencia de hacer visible los feminicidios que atormentan a sus comunidades, pueblos y naciones. En sus proclamas son categóricas y señalan con firmeza la complicidad del Estado y los sectores empresarios en tanto responsables directos de la arremetida que sufren las mujeres indígenas en el territorio. Citamos a continuación las palabras de la referente Moira Millán:

\begin{abstract}
...femicidio es el asesinato de una mujer por su condición de mujer como consecuencia de las condiciones de violencia patriarcal machista en las que vivimos, y ...feminicidio ...es una cuestión de genocidio hacia las mujeres que son el foco más vulnerable de los conflictos territoriales con las empresas extractivas (Millán,2017, p. 177).
\end{abstract}

Las mujeres indígenas denuncian públicamente situaciones de violencia en y contra sus cuerposterritorios en un contexto franqueado por el extractivismo; y ponen bajo la lupa la ausencia de relevamientos oficiales sobre los homicidios de lideresas y defensoras de los territorios comunitarios. En toda la región latinoamericana es posible observar cómo la expansión de las actividades extractivas (incluidos los agronegocios a gran escala) ha multiplicado los conflictos territoriales y ha disparado de manera alarmarte los índices de violencia. Los datos publicados por OXFAM revelan que durante el año 2017 más de doscientas personas "defensoras" (de los bienes comunes de la naturaleza) fueron asesinadas, de las cuales el 60\% eran de América Latina. Por su parte, en la misma dirección, Amnistía sostiene que en el período 20162017 fueron asesinadas 437 activistas de los Derechos Humanos, en 22 países, y el 75\% eran latinos/as y se manifestaban contra actividades extractivas (Valladares de la Cruz, 2019).

En este marco las mujeres indígenas que defienden sus territorios son, sin duda, una amenaza al orden establecido porque ponen en cuestión las estructuras de poder basadas en el género, demandan el reconocimiento de su identidad originaria y cuestionan, además, la redistribución desigual de recursos. Tal como hemos anticipado, la creciente expansión extractivista requiere nuevos espacios para la exploración y explotación de recursos, lo cual impacta de manera nociva sobre las poblaciones indígenas. En nombre 
del desarrollo económico los gobiernos progresistas y los de cuño neoliberal avanzan con el desmonte y la violación de las leyes de protección ambiental, como la Ley de Bosques. Esto ha dado lugar al hambre, la desnutrición y a la criminalización de referentes y líderes en todo el continente. Cabe mencionar algunos casos emblemáticos, como los feminicidios de Digna Ochoa (2001) en México, Berta Cáceres (2016) en Honduras y Cristina Linkopan (2013) en Argentina. Tina Linkopan, logko del lof Gelay Ko en Neuquén, fue una de las principales voces que denunciaron las consecuencias de la perforación del primer pozo para extracción de hidrocarburos no convencionales - por medio de la técnica conocida como fracking- en América Latina.

El terror étnico y de género imperante desde épocas de la conquista, cobra sentido y adquiere renovada utilidad en esta etapa de acumulación capitalista. Estamos en una situación de características similares al menos en términos de despojo y violencia, pues ante el auge extractivista observamos cómo el terror y la coerción son mecanismos aplicados desde las instituciones estatales y los sectores privados a fin de alcanzar o conseguir sus propósitos. La militarización de los territorios, la judicialización y la represión seguida de muerte se ve acompañada por una creciente masculinización de los espacios públicos. $\mathrm{Y}$, claramente, frente a este panorama las mujeres quedan expuestas a graves situaciones de violencia (Gartor, 2014). Otro caso emblemático que exhibe la estrecha vinculación presente entre el extractivismo y patriarcado fue el enjuiciamiento de la referente mapuce Relmu Ñamku, a finales de 2015.

\footnotetext{
Me duele estar acá sentada porque los verdaderos responsables no lo están porque tienen poder, tienen plata y hay toda una impunidad para que ellos no estén. Nosotros estamos acá porque somos pobres, somos indios y porque soy mujer (Ñamku, declaración o2 de noviembre de 2015)
}

La resistencia en el sur argentino del lof Winkul Newen contra la industria petrolera y, especialmente, la experiencia de lucha de Relmu demostraron cómo el imperialismo ha logrado avanzar sobre la geopolítica latinoamericana y, con ello, sobre las poblaciones originarias, los/as niños/as, las mujeres y sus cuerpos, es decir, sobre la vida. Las mujeres indígenas en Argentina son un verdadero estorbo para los sectores que tienen intereses en zonas ricas en recursos naturales. Por esta razón, de un tiempo a esta parte, han comenzado a denunciar la desatención de los organismos del estado y apuntan, sin miramientos, el silencio cómplice de las distintas expresiones del movimiento feminista en el país. En diferentes notas y entrevistas indagan en el motivo de dicho silenciamiento, de esta omisión selectiva que despliegan las instituciones estatales, los medios de comunicación y las organizaciones sociales. En sus reflexiones concluyen que la ausencia de políticas públicas, como así también de cobertura mediática y acompañamiento por parte de los feminismos (entre otros movimientos sociales) se debe, primordialmente, a la falta de acceso al sistema de justicia por parte de estas mujeres: "esta violencia no llega a los tribunales", asegura Moira Millán (2017).

Existen cuantiosas barreras que dificultan el acceso a derechos básicos como la salud, educación y justicia por parte de estas mujeres. Una de ellas, siguiendo a Méndez, podemos decir que está basada en el principio de "igualdad". Es el Estado la institución responsable de generar las medidas afirmativas que mejoren la situación de los sectores desaventajados y sin embargo, muchas veces, esto no sucede. La falta de visibilización de estas formas de violencia que se anudan -producto de desigualdades de género, étnicas/raciales y de clase- responde a una representación evolucionista de lo indígena enquistada en la estructura estatal argentina. De hecho, la presencia ausente (Gordillo y Hirsch, 2010) del mundo indígena ha legitimado históricamente la explotación de ciertos cuerpos y territorios. El discurso hegemónico de "Io nacional" ha arrojando todo vestigio indígena al pasado remoto (salvaje), dando lugar a una visión que se traduce en políticas públicas excluyentes y en un sistema de administración de justicia que no se adapta a las demandas de reconocimiento por lo que es incapaz de garantizar la continuidad del servicio.

La Declaración Universal de los Derechos Humanos de los Pueblos Indígenas, en su artículo décimo tercero, reza: “los Estados adaptarán medidas eficaces para asegurar la protección de ese derecho y también para asegurar que los pueblos indígenas puedan entender y hacerse entender en las actuaciones políticas, jurídicas y administrativas proporcionando para ello, cuando sea necesario, servicios de interpretación u otros medios adecuados". Pese a este reconocimiento formal, contamos con cuantiosas experiencias que demuestran el incumplimiento de la normativa vigente. Es el caso de las mujeres indígenas no hablantes en español quienes son víctimas de un sistema que literalmente golpea hasta matar como Juana Gómez asesinada en 2013 y Reina Maraz detenida en 2010 por el asesinato de su esposo. Esta joven migrante y quechua hablante, fue culpada de asesinar a su marido y obligada a parir en la cárcel, al respecto dice Bidaseca: "la historia de Reina Bejarano tiene que ver varios episodios que van complejizándose a medida que uno va queriendo comprender la trama de la vida. En esa trama se 
intersectan muchas discriminaciones que son las de ser mujer, boliviana, ser indígena, pobre, quechua hablante, analfabeta" (citada en Spinetta, 2014, p. 1).

En Argentina, y en toda la región latinoamericana, las vidas de las mujeres morenas, pobres, migrantes, trabajadoras e indígenas, no cuentan como vidas, se trata de cuerpos femeninos racializados y subalternos; por lo tanto sus muertes aparentemente no merecen ser lloradas (Gayón, 2014). Desde esta lógica y estética dominante, aquella que determina quién vive y quién no, estos cadáveres no importan, pues se trata de muertas que no encajan en los estándares que ameritan la indignación social, son malas víctimas. Según el Registro Nacional de Femicidios del Observatorio Mumalá, desde el 1 de enero al 9 de abril del corriente año se registraron 82 femicidios, lo que significa que cada 29 horas una mujer pierde la vida en Argentina. Sin embargo, no se sabe cuántas mujeres indígenas han perdido la vida víctimas de violencia sexista, ya que no hay cifras oficiales y los datos no están desagregados por pertenencia étnica. Estas muertas no existen, por tanto, no son cuantificadas.

si aún no podemos ser reconocidos como pueblos que existimos en esta Argentina, mucho menos podemos hablar de las garantías para resguardar los derechos de las mujeres y niñas (Ñamku, citada en Gago, 2019).

En síntesis, tal como dijimos arriba, los pueblos indígenas son grupos, colectivos, naciones que se ven afectadas en dos dimensiones relevantes en términos de justicia social, el reconocimiento y la redistribución. Si ir más lejos, podemos graficar este panorama al observar que en las últimas elecciones nacionales ninguna plataforma electoral recogió las demandas de este sector. No hubo propuestas que promovieran el fin del "hambre y la desnutrición" en las comunidades wichí del norte y, tampoco, las hubo orientadas a regularizar las tierras comunitarias mapuce en el sur. Hoy en día, las indígenas viven una ciudadanía restringida (Bareiro, 2018), ya que se enfrentan a numerosos obstáculos que impiden el pleno ejercicio de derechos y dificultan el acceso a condiciones de igualdad -real- de oportunidades (educación, justicia, salud, empleo, etc.). Sin embargo, como ellas mismas denuncian, éste es un "tema vedado" en Argentina.

\title{
Notas de cierre: una pandemia azota al mundo
}

\author{
Nada que merezca el nombre de "liberación de las mujeres" puede ser \\ alcanzado en una sociedad racista e imperialista \\ (Arruza, Bhattacharya y Fraser, 2019, p. 67)
}

Los feminicidios en América Latina nos invitan a reflexionar sobre una jerarquización social de los cuerpos-territorios. Dicha jerarquización, plantea Gayón (2015), configura y determina quién vive y quién muere. Esto es lo que los/as autores/as postestructuralistas han acordado en denominar necropolítica. Puntualmente, para Achille Mbembe la expresión última de la soberanía reside en el poder de decidir quién puede vivir y quién debe morir: "la soberanía consiste en ejercer un control sobre la mortalidad y definir la vida como el despliegue y la manifestación del poder" (2006, p. 20). En términos generales, este autor plantea la relación modernidad-terror y desde allí propone pensar cómo los estados modernos ejercen la soberanía, entendida como el derecho a matar. Para ello hace uso de tres nociones clave: biopoder, estado de excepción y estado de sitio. Tres conceptos que se han vuelto centrales en los últimos meses a escala global con motivo de la pandemia en curso, el COVID-19.

En relación a esto, entendemos preciso señalar, nuevamente, la importancia de advertir las continuidades históricas, pues las enfermedades importadas por los/as europeos a América llegaron a diezmar hasta el $95 \%$ de la población originaria durante los primeros años de la mal llamada Conquista de América. En la actualidad, en medio de una crisis ambiental producto del neoliberalismo tardío, se reconoce a nivel mundial que los territorios indígenas son los que han logrado conservarse de la devastación. Pese a ello, como hemos dicho a lo largo de este escrito, dichos territorios y las poblaciones que allí se desenvuelven se hallan amenazados por industrias extractivas, lo que da cuenta de que la colonialidad y el saqueo continúan intactos. No hay dudas de que el modelo neo-extractivista supone graves afectaciones al medio ambiente y la destrucción progresiva de las condiciones de vida de las poblaciones afectadas, sobre todo aquellas que se ubican en las denominadas "zonas de sacrificio".

Si seguimos con el planteo de Mbembe, observamos cómo el biopoder segrega a las personas y excluye de la esfera de interés público a aquellas que son susceptibles de ser "condenadas a muerte", 
sujetos/as sacrificables. Esta política de la muerte nos retrotrae a la conformación de los estados nacionales en toda América Latina y pone bajo la lente que la territorialización de los estados partió del genocidio indígena. Hoy en día, en un marco de expansión de las fronteras productivas, el Estado continúa su avanzada sobre los cuerpos territorios indígenas y, para ello, hace uso de ciertas políticas "de seguridad" orientadas a proteger los intereses de sectores económicos (al igual que en el siglo XIX), las cuales suponen la represión (y muerte), la criminalización y judicialización de las luchas sociales. En este contexto, el estado por acción u omisión expone a muerte a numerosas mujeres que defienden sus derechos como parte de pueblos y naciones pre-existentes. De este modo, los intereses económicos se imponen, una vez más, sobre la vida de poblaciones enteras, por lo que a nadie sorprende las pésimas condiciones de vida de estos grupos.

En Argentina, al igual que en muchos otros países, estamos ante una situación de excepcionalidad, puesto que nos encontramos en aislamiento social obligatorio con el fin de "aplanar la curva" de contagio del coronavirus. En este escenario la necropolítica se convierte en un concepto útil para explicar y comprender cómo las desigualdades estructurales e históricas definen cuáles cuerpos viven y cuáles no, ya que nos permite pensar en cómo el "virus" no afecta a todos/as por igual. Los sectores más desaventajados de la sociedad, aquellos que viven en la marginalidad, la pobreza, la precariedad laboral; aquellos que padecen la discriminación por razones sexuales y de género; aquellos que no son vistos por la prensa ni contemplados en los discursos políticos en épocas de campaña; esos son los que hoy están sufriendo las peores consecuencias de la pandemia. Y, claramente, dentro de estos grupos vulnerables encontramos a los pueblos indígenas y más aun a las mujeres. Las mujeres se nos presentan como las "nuevas" víctimas del desarrollo, aunque, ciertamente la violencia contra las mujeres defensoras es parte de las continuidades históricas, es una violencia normativa y funcional al orden de géneros patriarcal sobre el cual se erigen los estados liberales.

A propósito de lo antes dicho, la Recomendación General № 30 de la CEDAW reconoce que "los conflictos agravan las desigualdades existentes entre los géneros y el riesgo de las mujeres de ser víctimas de distintas formas de violencia de parte de agentes estatales y no estatales" (en Red Latinoamericana de Mujeres Defensoras de Derechos Sociales y Ambientales, s.f, p. 3). Los conflictos territoriales son, como señalamos anteriormente, centrales para comprender el rol de las mujeres indígenas en la actualidad y, por tanto, la crueldad que se expresa en sus cuerpos-territorios. Las mujeres indígenas sufren múltiples formas de desigualdad y discriminación por el hecho de ser mujeres indígenas, rurales o por vivir en zonas de resistencia o conflicto social, entre otras. Los feminicidios indígenas desnudan crímenes de estado, pues es el estado el responsable de dejar morir a estas mujeres y/o de exponerlas a situaciones de muerte como lo hace ahora, en pleno aislamiento.

Los feminismos denuncian diariamente cómo la emergencia por coronavirus ha incrementado la presión sobre las tareas de cuidados, el incremento de las denuncias por violencia de género que no cesa. Las estadísticas son verdaderamente preocupantes, los femicidios van en aumento pero nada se sabe sobre la realidad que atraviesan las mujeres indígenas. ¿Cómo afecta el COVID-19 a las comunidades? ¿Qué ocurre con la violencia de género en el contexto actual en las comunidades originarias? El silencio cómplice de numerosos sectores como los medios de comunicación, pone en evidencia que hay muertes que importan y otras que no. Cabe recordar que pocos meses antes de la preocupación y el pánico por el COVID-19, se denunciaba y exigía la emergencia sanitaria en Salta por la sucesión de muertes a causa de desnutrición en comunidades wichís. Esta situación no se ha modificado, las condiciones materiales de vida de estas comunidades continúan siendo nefastas y se han visto agravadas por la pandemia. Numerosas comunidades indígenas de Argentina y América Latina están expuestas a la desnutrición y a enfermedades (como el dengue, la malaria, etc.) que deterioran su sistema inmunitario y los/as convierte en población de altísimo riesgo. A fin de graficar la situación podemos mencionar que durante la expansión de la gripe $\mathrm{H}_{1} \mathrm{~N}_{1}$ solamente en Estados Unidos y Canadá la mortalidad de indígenas fue de 3 a 7 veces mayor a la de la población no indígena.

La pandemia ha puesto sobre el tapete la violencia patriarcal a la que están sometidas las mujeres y la exclusión histórica que padecen los pueblos indígenas, los cuales se encuentran a la deriva, expuestos a condiciones de extrema vulnerabilidad. A todo esto debemos agregar las formas de represión que el estado perpetúa sobre estos grupos, ya sea por medio de la represión policial o a través de prácticas persecutorias. Es imposible pensar en términos de justicia social y de género si no advertimos la urgencia de observar las desigualdades estructurales que se plasman en los cuerpos-territorios de las mujeres indígenas. Hacer lugar a las demandas por reconocimiento de las originarias es una tarea pendiente también para los feminismos. La ligazón histórica entre feminismo y racismo, dicen Arruza, Bhattacharya y Fraser (2019), ha adoptado diversas "formas sutiles" y se ha filtrado a través de la universalización de la 
situación de las mujeres, pensadas todas como blancas y de clase media.

Proclamar de forma abstracta la sororidad global es contraproducente; al tratar lo que en realidad es el objetivo del proceso político como si ya estuviera dado desde el comienzo, estas declaraciones transmiten una falsa impresión de homogeneidad. La verdad es que, aunque todas padecemos en esta sociedad capitalista misógina, esa opresión toma diferentes formas en cada una de nosotras (Arruza, Bhattacharya y Fraser, 2019, p. 72).

En Argentina podemos visualizar cómo cierto etnonacionalismo intenta imponerse en el espacio político feminista por excelencia, el Encuentro "Nacional” de Mujeres, ignorándose sistemáticamente las demandas de plurinacionalidad de numerosos grupos. En este sentido consideramos importante afirmar que a nuestro criterio, siguiendo el pensamiento de las autoras antes citadas, para pronunciarnos como feministas antirracistas y antiimperialistas debemos asumirnos anticapitalistas. Las reivindicaciones de las mujeres indígenas no se reducen a una única esfera, no requieren solamente de políticas que reconozcan las diferencias culturales e identitarias sino que suponen, también, un profundo cuestionamiento al modelo de desarrollo capitalista, al Estado liberal y con ello a la Democracia y a la noción de Ciudadanía. Para cerrar deseamos compartir una breve reflexión publicada por la Confederación Mapuce de Neuquén (2020) sobre la coyuntura argentina, pues entendemos que estas palabras sintetizan en buena medida el espíritu de este escrito:

"Hoy estamos en el mismo barco"

No! No estamos en el mismo barco, estamos en el mismo mar. Unos en yate, otros en lancha, otros en salvavidas y otros nadando con todas las fuerzas que nos quedan. No nos engañemos.

\section{Conflict of interest}

No potential conflict of interest is reported by the author(s).

\section{Funding}

There is no financial assistance in studies from external parties.

\section{Acknowledgements}

$\mathrm{N} / \mathrm{A}$

\section{REFERENCIAS}

Anthias, Floya (2006). Género, etnicidad, clase y migración: interseccionalidad y pertenencia translocalizacional. En, P. Rodriguez, Feminismos periféricos (pp. 49-68). Granada: Editorial Alhulia. Editorial.

Arruza, C., Bhattacharya, T., y Fraser, N. (2019). Feminismo para el 99\%. Un manifiesto. Buenos Aires: Rara Avis

Berlanga Gayón, M. (2014). El color del feminicidio: de los asesinatos de mujeres a la violencia generalizada. El Cotidiano, (184), 47-61. https://www.redalyc.org/pdf/325/32530724003.pdf

Berlanga Gayón, M. (2015). Feminicidio: el valor del cuerpo de las mujeres en el contexto latinoamericano actual. Pelícano, (1), 6-18.http://revistas.bibdigital.uccor.edu.ar/index.php/pelicano/article/view/1022

Bidaseca, K. (2019). 1800 muertas por feminicidio. 700 desaparecidas y más... cuando no era de esperar que sobreviviéramos. En Bidaseca, K. et al, \#NiUnaMenos. Vivas nos queremos (pp. 35-39). Buenos Aires: Milena Caserola.

Carosio, A. (2011). Muchas y Rebeldes: memoria de las mujeres en el proceso independentista. Seminario de Pensamiento Feminista Latinoamericano del Consejo Latinoamericano de Ciencias Sociales (CLACSO).

Confederación Mapuche de Neuquén [@XAWVNKO]. (2020, 26 de abril). Hoy estamos en el mismo barco" No! No estamos en el mismo barco, estamos en el mismo mar. Unos en yate, otros en lancha, otros en salvavidas y otros nadando con todas las fuerzas que nos quedan. No nos engañemos [Publicación de Facebook]. https://www.facebook.com/XAWVNKO/

Federici, S. (2010). Calibán y la bruja: mujeres, cuerpo y acumulación originaria. Madrid: Traficantes de Sueños.

Gago, V. (2019). La potencia feminista: o el deseo de cambiarlo todo. Argentina: Tinta Limón Ediciones.

Gargallo, F. (2015). Feminismos desde Abya Yala: ideas y proposiciones de las mujeres de 607 pueblos en nuestra América. México: Universidad Autónoma de la Ciudad de México.

Gartor, M. (2014, 14 de febrero). Feminismo reactiva la lucha contra el 'extractivismo' en América Latina. Rebelión. http://www.rebelion.org/noticia.php?id=181047 
Gordillo, G., y Hirsch, S. (2010). La presencia ausente: invisibilizaciones, políticas estatales y emergencias indígenas en Argentina. En, G. Gordillo \& S. Hirsch (Comps.), Movilizaciones indígenas e identidades en disputa en la Argentina (pp. 15-38). Buenos Aires: La Crujía.

Harvey, D. (2004). El nuevo imperialismo. España: Ediciones Akal.

Lagarde, M. (2005). El feminicidio, delito contra la humanidad. https://bit.ly/2VRhCm2

Lenton, D. (2010). La 'Cuestión de los Indios' y el genocidio en los tiempos de Roca: sus repercusiones en la prensa y la política. En O. Bayer (Coord.), Historia de la crueldad argentina. Julio Argentino Roca y el genocidio de los Pueblos Indígenas (pp. 29-50). Buenos Aires: El Tugurio.

Mbembe, A. (2006). Necropolítica. Barcelona: Melusina.

Méndez, J. (2000). El acceso a la justicia, un enfoque desde los derechos humanos. En, J. Thompson (Coord.), Acceso a la justicia y la equidad: estudio en siete países de América Latina (pp. 15-22). Costa Rica: Banco Interamericano de Desarrollo/Instituto Interamericano de Derechos Humanos.

Millán, M. (2011). Mujer Mapuche. Explotación colonial sobre el territorio corporal. En K. Bidaseca (Comp.), Feminismos y poscolonialidad. Descolonizando el feminismo desde y en América Latina (pp. 291-306). Buenos Aires: Ed. Godot.

Millán, M. (2019). Ausencia de la voz indígena. En, K. Bidaseca et al, \#NiUnaMenos. Vivas nos queremos (pp. 177180). Buenos Aires: Milena Caserola.

Pequeño, A. (2007). Imágenes en disputa. Representaciones de mujeres indígenas ecuatorianas [Tesis de Maestría, FLACSO Ecuador] Repositorio institucional, https://bit.ly/3cVC2zG

Quijano, A. (1999). Colonialidad del poder, cultura y conocimiento en. América Latina. Dispositio, 24(51), 137148. https://bit.ly/3f7iQAX

Red Latinoamericana de Mujeres Defensoras de Derechos Sociales y Ambientales (s.f). Informe sobre la situación de riesgo y criminalización de las defensoras del medioambiente en América Latina. www.redlatinoamericanademujeres.org

Roux, R. (2008). Marx y la cuestión del despojo. Claves teóricas para iluminar un cambio de época. Revista herramienta, 38, 61-74. https://www.redalyc.org/pdf/124/12426097008.pdf

Segato, L. (1998). Identidades políticas / Alteridades históricas una crítica a las certezas del pluralismo global. RUNA, Archivo Para Las Ciencias Del Hombre, 23(1), 239-275. https://doi.org/10.34096/runa.v23i1.1304

Segato, R. (2004). Territorio, soberanía y crímenes de segundo Estado: la escritura en el cuerpo de las mujeres asesinadas en Ciudad Juárez. Brasilia: Universidad de Brasilia.

Segato, R. (2006). Que és un feminicídio: notas para un debate emergente. Brasilia: Universidade de Brasilia, Departamento de Antropología. ly/2Wcbtj5

Segato, R. (18 de febrero de 2016). Peritaje antropológico cultural de género. Recuperado de: https://bit.

Seifert, R. (1996). The Second Front. The logic of sexual violence in wars. Women 's Studies International Forum, 19, 35-43. https://doi.org/10.1016/0277-5395(95)00078-x

Seoane, J. (2012). Neoliberalismo y ofensiva extractivista. Actualidad de la acumulación por despojo, desafíos de Nuestra América. Theomai, (26). https://www.redalyc.org/articulo.oa?id=12426097006

Spinetta, B. (2014, 14 de abril). Las Barbaries sobre Reina Maraz. Comunicación para la igualdad. https:// comunicarigualdad.com.ar/las-barbaries-sobre-reina-maraz/

Vásquez, P. T. (2009). Feminicidio. México: Oficina en México del Alto Comisionado de Las Naciones Unidas para los Derechos Humanos.

Valladares de la Cruz, L. (2019). Mujeres indígenas entre guerras: viejas y nuevas expresiones de la violencia. Encartes, 2 (4), 145-174. https://bit.ly/2SiT1UO

Vargas, V. (2011). Democracia con tiempos de beligerancia: los retos en la construcción de ciudadanía de las mujeres en el siglo XXI [Presentación] Foro Hemisférico: Liderazgo de las mujeres para la democracia de ciudadanía, Centro Flora Tristán- Articulación Feminista MARCOSUR.

Zambrini, L. (2015). Diálogos entre el feminismo postestructuralista y la teoría de la interseccionalidad de los géneros. Revista Punto Género, (4), 43-54. https://doi.org/10.5354/0719-0417.2014.36408

\section{Author:}

Suyai García Gualda. Docente en FADECS-Universidad Nacional del Comahue. 